\title{
Contributing Factors for Underutilization of Inhaled Corticosteroids Among Asthmatic Patients Attending at Adama Hospital Medical College, Adama, Ethiopia
}

This article was published in the following Dove Press journal:

Journal of Asthma and Allergy

\section{Sileshi Tadesse ${ }^{\prime}$ \\ Zinash Beyene ${ }^{2}$}

'Department of Pharmacology, Yekatit 12 Hospital Medical College, Addis Ababa, Ethiopia; ${ }^{2}$ Department of Pharmacy, Rift Valley University, Adama Campus, Adama, Ethiopia
Correspondence: Sileshi Tadesse Department of Pharmacology, Yekatit 12 Hospital Medical College, Addis Ababa, Ethiopia

Email silejetu@gmail.com
Introduction: Inhaled corticosteroids (ICSs) are a cornerstone medicine for preventive therapy of persistent severe asthma. Although ICs are very effective for the treatment of severe persistent asthma, the majority of the prescribers worldwide aren't aware of ICs use for the treatment of severe persistent asthma.

Objective: To evaluate factors contributing to underutilization of ICS by asthmatic patients. Methods: Patient interview was conducted among asthmatic patients using a cross-sectional study design who were attending at the Adama Hospital Medical College from March 1 to July 25, 2017. The total number of patients involved in the study was 94. Semi-structured questionnaire through patient interview was used for data collection and data from physicians who were working at the chest clinic of AHMC were collected by self-administered semistructured questionnaire focusing their perspectives and experiences on patients' ICS.

Results: Generally $73.5 \%$ of underutilization of ICS was reported from the total number of patients involved in the study according to the patient's perception. Monthly income, comorbid disease, and behaviors of ICS use were the main factors contributing to underutilization of ICS. According to patient's report, some of the reasons for underutilization of ICS were unaffordability, using the drugs only when symptoms appear, inaccessibility, side effects and recommendation by physicians. There were also similar reports by the physicians working in the AHMC.

Conclusion: In our study setting, prevalence of underutilization of ICS was high and the contributing factors were increased cost of ICS, inaccessibility of ICS, poor knowledge of the patients on asthma disease and ICS, bad attitude toward ICS, and lack of recently reviewed local guideline for asthma treatment. Thus, concerned experts need to take actions that guarantee accessibility of ICS at a reasonable price and increase awareness of patients about asthma disease and use of ICS.

Keywords: inhalation corticosteroids, underutilization of ICS, asthma, AHMC

\section{Plain Language Summary}

Asthma is a chronic inflammatory disorder of the airways in which a person's airways become inflamed, narrow, swell, and produce extra mucus, which makes it difficult to breathe. There are diverse classes of drugs for treatment of bronchial asthma from which inhaled corticosteroids play a great role in controlling the disease. Inhaled corticosteroids (ICS) use has key a part in the management of persistent asthma. Many factors can affect prevalence of ICS use including underutilization of ICS. Varieties of factors associated with 
underutilization of ICS include monthly income, comorbidity and manner of ICS use (whether ICS was used alone or in combination with long acting beta-2 agonists). Too expensive drugs, inaccessibility of ICS, poor knowledge of the patient's on asthma disease and ICS, bad attitude toward ICS, and lack of recently reviewed local guideline for asthma treatment are the major contributing factors for underutilization of inhaled corticosteroids.

\section{Introduction}

According to the global initiative for asthma management and prevention (GINA) asthma is defined as a chronic inflammatory disorder of the airways, in which many cells and inflammatory mediators play a great role. The chronic inflammation is related with bronchial sensitivity that leads to recurring episodes of, difficulty in breathing, chest pain, wheezing, and cough, mainly at night or in the early morning. Irregular extensive airway blockade in the lung is often reversible either spontaneously or with treatment and usually linked with these symptoms. In most cases the diagnosis of asthma is a clinical-based method. The clinical-based diagnosis usually includes symptoms of wheeze, cough, chest pain, and difficulty in breathing with irregular airway obstruction is sufficient to make the diagnosis of the disease. ${ }^{1-4}$

Bronchial asthma is one of the diseases representing a substantial economic and social burden throughout the world and causing chronic morbidity and mortality worldwide. ${ }^{5}$ Probably one of the major causes for bronchial asthma related morbidity is poor adherence to drug treatment. $^{6,7}$ Inhaled corticosteroids (ICSs) are the preferred choice for long-term treatment in pediatrics and adults as explained in different guidelines. ICSs have shown to be the best accepted and safe at recommended $\operatorname{doses}^{8}$ and evidence in different literature supports that ICSs are beneficial in decreasing symptoms and reducing risk of death. Different studies showed that underuse of ICSs is most common among patients with severe persistent asthma. ${ }^{9,10}$ As a result these studies propose that the underuse of long-acting controller drugs may aggravate asthma control in the long-term. This type of effect mostly causes an increase in health-care consumption by the patient in the form of increased physician visits and more frequent hospital admissions for asthma-related complications. ${ }^{10,11}$ Hence, incorrect uses of ICS and poor adhere to treatment has led to unwanted consequences for the patients. ${ }^{12}$ The problem is significant in developing countries like Ethiopia where asthma is mostly undertreated, leading to high morbidity and mortality. ${ }^{5}$
Inadequate and lack of access to ICS highly decreases the likelihood of effective control of asthma in many parts of the world. This may show in part why in areas such as in SubSaharan Africa, where access to medication may be poor, severe asthma is more common than otherwise might be predicted. $^{13}$

In Ethiopia this problem is another burden for the country next to communicable diseases. ${ }^{14}$ A study conducted in south west Ethiopia showed $2 \%$ of outpatient and $5.4 \%$ of medical admission accounted for asthma. ${ }^{14,15}$ The use of ICS among total asthmatic patients was $3.8 \%$ as shown in a study in Jimma University Specialized Hospital ${ }^{16}$ and underutilization of ICS (24\%) is a significant cause of uncontrolled asthma and asthmatic attacks as reported in a study at Tikur Anbessa Specialized Hospital. However, the studies did not indicate factors that are contributing to the problem. ${ }^{17}$

\section{Operational Definition}

\section{Inhaled Corticosteroids}

ICSs are anti-asthmatic drugs containing either corticosteroid alone or in combination with LABA.

\section{Underutilization of Inhaled Corticosteroids}

The use of ICS below the regimen recommended by GINA guideline for the specific step of asthma management or primary nonadherence or discontinuation in all or not having prescription for ICSs in case of persistent asthma patients.

\section{Primary Nonadherence}

Patients who were prescribed ICSs but never filled the prescription.

\section{Optimal Regimen}

The dose and frequency of ICS recommended by GINA guideline for the specific step of asthma management.

\section{Suboptimal Regimen}

The dose and frequency of ICS below recommended by GINA guideline for the specific step of asthma management.

\section{Materials and Methods Study Setting and Period}

Adama is one of the towns of Oromia regional state, East Shewa zone and located $99 \mathrm{~km}$ from Addis Ababa, Ethiopia. A facility-based prospective cross-sectional study involving patient interview and chart review was conducted in AHMC 
to evaluate factors related with underutilization of ICS in asthmatic patients attending at Adama Hospital Medical College from March 1 to July 25, 2017.

\section{Study Protocol}

The study population comprised of a total of 94 asthmatic patients who fulfilled inclusion criteria and attended the chest clinic of AHMC for their regular follow-up during the study period. Eight physicians (two internists, three residents, and three general practitioners) working at the chest clinic were requested to complete semi-structured questionnaires for qualitative data. Those Patients with persistent asthma of age greater or equal to 18 and asthma duration greater than one year were included in the study. Patients who had one or more of the following comorbidities, congestive heart failure, COPD, pulmonary hypertension and pulmonary embolism were excluded from the study because of the manifestations of the similar symptoms leading to misdiagnosis of the disease (asthma). Those patients who discontinued their follow-up for greater than three months at the chest clinic of the hospital were also excluded from the study.

A structured questionnaire was adopted by making appropriate modifications for data collection from earlier studies to serve our study purpose. ${ }^{18,19}$ The classification and assessment of stage of asthma disease was done using the Global Initiative for Asthma (GINA) criteria. To collect data and associated factors from physicians a selfadministered semi-structured questionnaire focusing on ICS practice was used (Annex II). Pretest using the questionnaire was performed on $5 \%$ of the sample size prior to study period. Patients who participate in the pretest were not included in the final sample of the study. The questionnaires were revised and checked every day for completeness in addition to data collector training on how effectively gathering information from the patients, and essential feedback was provided to the data collector. Each completed questionnaire was assigned a unique code (Annex I).

The institutional review board (IRB) of Rift Valley University has checked that the research is done in accordance with the Declaration of Helsinki. The patients were informed about the purpose and importance of the study prior to initiation of data collection and written agreement was made for all patients. The recorded card number of the patients was used as identification and name of the patients was excluded to retain and respect confidentiality of all information obtained. The data entry and analysis was made using Statistical Package for Social Science (SPSS) version 20 for windows. Data were presented by using tables and figures.

To determine knowledge of the respondents, for each question on asthma and ICS, one point was given for 'Yes' responses and zero for 'No' and "I don't know" responses. Sum of the points were computed for each patient from a total score of five. The cut-off point used for knowledge of asthma and ICS was the median score. Attitude toward asthma and ICS was categorized into positive and negative attitude by calculating sum of the attitude questions from 13 and 25 , respectively.

\section{Results}

\section{Sociodemographic Characteristics of the Respondents}

A total of 94 asthmatic patients fulfilling the criteria were interviewed and mean of their age was 45.3 years that tied with in the interval between 33.73 and 56.87 years old (45.3 $\pm 11.57 \mathrm{SD})$. From the total $69.2 \%$ were females and the rest $30.9 \%$ were males. Lower than half of the respondents (46.8\%) were married and majority of the study participants (69.2\%) had attended school and finished their educational career with a minimum of primary education and the median monthly income level of the participants was 1100 ETB with a range of 700 to 7000 ETB.

\section{Disease Characteristics of the Asthmatic Patients}

The mean duration of asthma for this study group during the study period was 19.8 years and more than half $(59.6 \%)$ of study population had asthma of greater than 17 year's duration. The severity category of asthma was found to be $30.9 \%$ mild persistent, $41.5 \%$ moderate persistent and $26.6 \%$ severe persistent. About $67 \%$ of the respondents had one or more comorbid diseases and less than half (39.4\%) of the study participants were on one or more medications other than anti-asthmatics.

\section{Prevalence of ICS Use}

As shown in Table 1, it was found that $88.3 \%$ of the respondents were ordered to take ICS. Out of 83 prescriptions containing ICS, almost ICS alone accounted for $69.9 \%$ whereas ICS with LABA took a high proportion (30.1\%). From 83 patients with ICS prescriptions, 56.6\% reported that they were taking ICS during the data collection period 
Table I Prevalence of ICS Use in AHMC from March I to July 25, $2017(n=94)$

\begin{tabular}{|l|l|}
\hline Prevalence of ICS Use & Number (\%) \\
\hline $\begin{array}{l}\text { ICS prescribed } \\
\text { Yes }\end{array}$ & $83(88.3)$ \\
No & $I I(I I .7)$ \\
\hline $\begin{array}{l}\text { Types of ICS products prescribed (n=83) } \\
\text { ICS alone }\end{array}$ & $58(69.9)$ \\
ICS with LABA & $25(30.1)$ \\
\hline $\begin{array}{l}\text { ICS prescribed patients (n=83) } \\
\text { Patients using ICS }\end{array}$ & $47(56.6)$ \\
Patients who discontinued using ICS & $24(20.5)$ \\
\hline Patients who were using ICS (n=47) & $12(22.9)$ \\
Optimal regimen & $25(53.2)$ \\
Suboptimal regimen & $22(46.8)$ \\
\hline Underutilization of ICS (n=83) & \\
Yes & $6 I(73.5)$ \\
No & $22(26.5)$ \\
\hline
\end{tabular}

Abbreviations: ICS, inhaled corticosteroids; AHMC, Adama Hospital Medical College; LABA, long-acting $\beta 2$ agonists.

while $20.5 \%$ of them started to use ICS but discontinued. Patients $(22.9 \%)$ with ICS prescriptions reported that they never began to use ICS despite physician's orders. Among 47 asthmatic patients who were ever users of ICS, $46.8 \%$ were prescribed with dosage regimen below the GINA guideline recommendations. Generally speaking, from the patients' point of view, it was revealed that $73.5 \%$ of ever ICS users reported underutilization of ICS.

\section{Attitude and Knowledge of the Patients Toward Asthma and ICS}

From the study it was found that $54.3 \%$ of users of ICS have good knowledge about asthma whereas the rest (45.7\%) had poor knowledge. Regarding their attitudes towards asthma, $92.6 \%$ felt positive when they thought about their illness. It was found that $67 \%$ had good knowledge about ICS among 64 ever ICS users, while the rest (33\%) had poor knowledge. About $56.4 \%$ the patients had positive feelings about ICS whereas the remaining (43.6\%) had negative beliefs about ICS (Table 2).

\section{Association Between Different Variables and Underutilization of ICS}

As shown in Table 3, monthly income of the participants was significantly associated with underutilization of ICS
Table 2 Attitude and Knowledge of the Patients Toward Asthma and ICS in AHMC March I to July 25, $2017(n=94)$

\begin{tabular}{|l|l|}
\hline $\begin{array}{l}\text { Attitude and Knowledge Toward Asthma and } \\
\text { ICS }\end{array}$ & $\begin{array}{l}\text { Number } \\
\text { (\%) }\end{array}$ \\
\hline $\begin{array}{l}\text { Asthma knowledge } \\
\text { Good } \\
\text { Poor }\end{array}$ & $5 I(54.3)$ \\
\hline $\begin{array}{l}\text { Attitude towards asthma } \\
\text { Positive }\end{array}$ & $43(45.7)$ \\
Negative & \\
\hline $\begin{array}{l}\text { ICS Knowledge } \\
\text { Good }\end{array}$ & $87(92.6)$ \\
Poor & $7(7.4)$ \\
\hline Attitude towards ICS & $31(33)$ \\
Positive & $63(67)$ \\
Negative & $53(56.4)$ \\
\hline
\end{tabular}

indicating that those who had monthly income of less than or equal to $1500 \mathrm{ETB}$ were about eight times more likely to underutilize ICS than those who had more than 3500 ETB (95\%CI: 2.12-29.23). In this study, it was found that patients who did not have formal education were about twice as likely to underutilize ICS than those who had a college diploma or above (95\%CI: 0.91-4.21). Patients who had been prescribed ICS alone were about five times more likely to underutilize than those had been prescribed with the combination of ICS and LABA $(95 \% \mathrm{CI}$ : $1.65-$ 10.32). Patients with comorbidity had about twice the chance of underutilizing ICS compared to patients with no comorbidity $(95 \% \mathrm{CI}: 1.02-4.67)$. The other factor which has significant association was use of other medication. Those with other medication were about four times more likely to underutilize ICS than who do not use other medication (95\% CI: 1.68-9.45) in addition to drugs for asthma. Again patients with severe persistent asthma compared to those with mild and moderate asthma were about twice as likely to underutilize ICS (95\%CI: 0.95-7.50). From Table 3 it is also possible to see there is significant association with duration of asthma.

\section{Patient's Reasons for Underutilization of ICS}

We had asked our study participants about the reasons for underutilization of ICS as it was depicted in Figure 1. About one-third of our respondents (34.5\%) reported that their reason for underutilization of ICS was it not being affordable while other reasons mentioned were not available $(29.5 \%)$, use only when symptoms arise $(26.2 \%)$, fear 
Table 3 Multivariate Analysis of Factors Associated with Underutilization of Inhaled Corticosteroids in AHMC from March I to July 25, $2017(n=94)$

\begin{tabular}{|c|c|c|c|c|}
\hline \multirow{2}{*}{ Variables } & \multicolumn{2}{|c|}{ ICS Underutilization } & \multirow[t]{2}{*}{ COR $(95 \% \mathrm{Cl})$} & \multirow[t]{2}{*}{ AOR } \\
\hline & Yes (\%) & No (\%) & & \\
\hline \multicolumn{5}{|l|}{ Age } \\
\hline $18-30$ & $6(75)$ & $2(25)$ & 1.00 & 1.00 \\
\hline $31-43$ & $28(77.8)$ & $8(22.2)$ & 1.56 & $\mathrm{I} .43$ \\
\hline $44-56$ & $33(86.8)$ & $5(13.2)$ & $1.97 *(0.9 I-4.2 I)$ & $1.54(0.54-4.15)$ \\
\hline $57-69$ & $2(16.7)$ & $10(83.3)$ & 1.00 & 1.00 \\
\hline \multicolumn{5}{|l|}{ Duration of asthma in years } \\
\hline$\leq 17$ & $29(55.8)$ & $23(44.2)$ & 1.00 & 1.00 \\
\hline$>17$ & $40(95.2)$ & $2(4.8)$ & $2.65 *(1.31-4.56)$ & $2.57^{*}(0.58-4.53)$ \\
\hline \multicolumn{5}{|l|}{ Educational status } \\
\hline No formal education & $29(93.5)$ & $2(6.5)$ & $1.96 *(0.9 I-4.2 I)$ & $1.49(0.54-4.15)$ \\
\hline Primary education & $23(62.2)$ & $14(37.8)$ & 1.00 & 1.00 \\
\hline High school & II (64.7) & $6(35.3)$ & 1.00 & 1.00 \\
\hline College diploma and above & $6(66.7)$ & $3(33.3)$ & 1.00 & 1.00 \\
\hline \multicolumn{5}{|l|}{ Comorbidity } \\
\hline Yes & $46(79.3)$ & $12(20.7)$ & $2.17^{*}(1.02-4.67)$ & $3.15^{*}(1.12-8.78)$ \\
\hline No & $23(64)$ & $13(36)$ & 1.00 & 1.00 \\
\hline \multicolumn{5}{|l|}{ Use of other medications } \\
\hline Yes & $36(85.7)$ & $6(14.3)$ & $4.23 *(1.68-9.45)$ & 1.00 \\
\hline No & $33(63.5)$ & $19(36.5)$ & 1.00 & $4.12 *(1.39-11.46)$ \\
\hline \multicolumn{5}{|l|}{ Severity of asthma } \\
\hline Mild persistent & $26(8 \mid .3)$ & $6(18.7)$ & 1.00 & 1.00 \\
\hline Moderate persistent & $19(5 \mathrm{I} .4)$ & $18(48.6)$ & 0.63 & 0.534 \\
\hline Severe persistent & $24(96)$ & I (4) & $2.64 *(0.95-7.50)$ & $3.18^{*}(0.87-11.85)$ \\
\hline \multicolumn{5}{|c|}{ Types of ICS products prescribed } \\
\hline ICS alone & $59(89.4)$ & $7(10.6)$ & $4.87 *(1.65-10.32)$ & $4.57 *(1.43-12.54)$ \\
\hline ICS with LABA & $10(35.7)$ & $18(64.3)$ & 1.00 & 1.00 \\
\hline \multicolumn{5}{|l|}{ Monthly income status } \\
\hline$\leq 1500$ & $52(83.8)$ & $10(16.2)$ & $7.89 *(2.12-29.23)$ & $5.43 *(1.02-22.01)$ \\
\hline$|50|-3500$ & $14(60.8)$ & $9(39.2)$ & 2.31 & 1.36 \\
\hline$>3500$ & $3(33.3)$ & $6(66.7)$ & 1.00 & 1.00 \\
\hline
\end{tabular}

Notes: *Variables with significant association, Use of other medication (use of additional drugs concomitantly with asthma drugs); ; Ethiopian per capita income is 18,4 I8.05 ETB, price of beclomethasone oral spray (Beclate) $200 \mu \mathrm{g}$ in Ethiopia is 130 ETB.

Abbreviations: ICS, inhaled corticosteroids; AHMC, Adama Hospital Medical College,; COR, crude odds ratio; AOR, adjusted odds ratio.

of side effects (4.9\%) and physician recommendations $(4.9 \%)$.

\section{Physician's Recommended Regimen for Different Severity Category of Asthma}

As seen from Table 4 more than $60 \%$ of the physicians preferred the combination of salbutamol PRN and beclomethasone puff for mild persistent asthma whereas about $50 \%$ of the physicians reported to prescribe the combination of salbutamol PRN + beclomethasone puff or salbutamol PRN + fluticasone puff + salmeterol puff. Almost half of the physicians used the combination of salbutamol PRN + salmeterol puff + oral steroids + fluticasone puff as their first choice for treatment of severe persistent asthma.

\section{Report from Physicians for Underutilization of ICS by the Patients}

From a total of eight physicians, almost all of the them prefer ICS alone or in combination with LABA as the first 


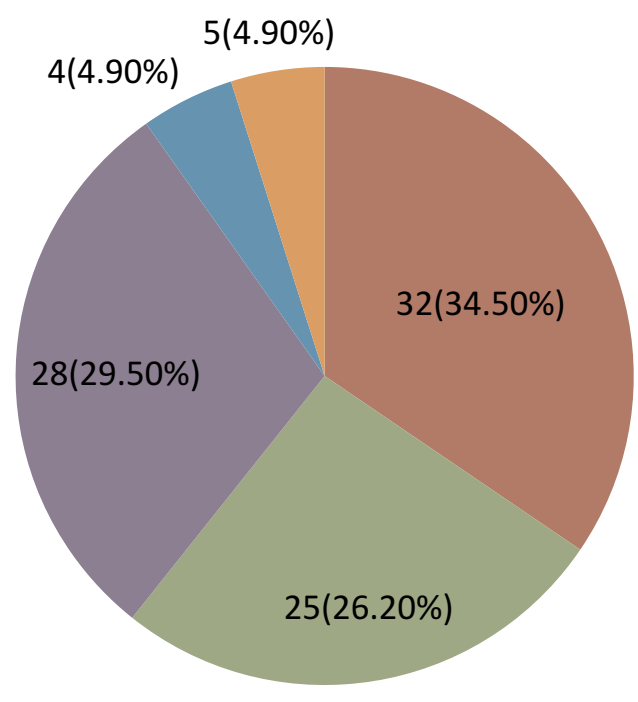

- Drug not affordable

" Use only when symptoms arise

- Not available

- Fear of side effects

- Physicians' recommendations

Figure I Patient's reasons for underutilization of ICS.

choice for treatment of persistent asthma. All of them have responded yes when asked in prescribing other drugs in some circumstances other than ICS. Four physicians reported that unavailability and patients' inability to afford ICS as a driving force to prescribe other drugs. Most of the physicians (6) replied that they would prescribe continuous use of ICS for patients even in the absence of symptoms. Asked if they would make any modification on initial regimen, most of them responded that they would consider decreasing the dose to the least possible dose (5) and maintain initial regimen (1). When asked about adequate utilization of ICS from the patients' side, all of them responded "no", and mentioned different reasons for the problem. But most of them (6 physicians) reported unaffordability of ICS as a main obstacle for prescribing ICS. The other reasons for underuse of inhaled corticosteroids from the perspective of the patients were fear of adverse drug reaction and dependence with ICS as pointed out by some physicians and lack of awareness and failure to advise patients properly about the drug from physicians' side as a cause.

\section{Discussion}

The objective of this study was to evaluate factors contributing to underutilization of ICS by asthmatic patients, at the chest clinic of AHMC. The evidence of their antiinflammatory effect ${ }^{20,21}$ makes ICSsthe preferred drugs in case of moderate or severe asthma as mentioned in the recent edition of GINA. ${ }^{22}$ The benefit of these drugs was decreased if initiated after two years of asthma occurrence. ${ }^{8,23}$
In this study underuse of ICS was found to be $73.5 \%$ as reported from the patients' perspective. The finding is in line with a study done in the US where using low dose ICS by the patients $(74 \%) .{ }^{24}$ Yet, the main dissimilarity between these two studies is that in the later study physicians recommendations are the major cause for underutilization of ICS. This is not the case in our study where underutilization of ICS was primarily due to inability to afford the drugs, fear of side effects, discontinuation, and unavailability of the drugs. Moreover, the finding shows much higher underutilization of ICS compared to a French study which reported only about $38 \%$ ICS underutilization. ${ }^{25}$ The difference seen is probably attributable to disparities between the two study settings.

The prevalence of ICS use in this study was $88.3 \%$ and the finding is higher than in studies done in Jimma (3.8\%), India (30.9\%), and North Africa (Algeria, Morocco, and Tunisia) (26.1\%). ${ }^{26-28}$ This might be partly due to socioeconomic differences between these countries. Only those patients with persistent severe asthma were included and most likely get ICS prescription which may lead to underestimation of prevalence of ICS use. Underutilization of ICS in the present study $(73.5 \%)$, however, is much higher than in a study done in the same setting, which reported only about $24 \%$ underutilization. ${ }^{16,27}$ This might be due to the fact that appropriateness of the patient's regimen was not taken into account in the previous study, which might have led to underestimation of ICS underutilization compared to this study.

It is known that cost of the medication is one of the main factors which affects the utilization pattern of the 
Table 4 Physician's Recommended Regimen for Different Severity Category of Asthma in AHMC from March I to July 25, $2017(n=94)$

\begin{tabular}{|c|c|}
\hline $\begin{array}{l}\text { Category of Asthma and Recommended } \\
\text { Regimen }\end{array}$ & $\begin{array}{l}\text { Number of } \\
\text { Physicians }\end{array}$ \\
\hline \multicolumn{2}{|l|}{ Mild persistent asthma } \\
\hline Salbutamol PRN & 2 \\
\hline $\begin{array}{l}\text { Salbutamol PRN + beclomethasone } 200 \mu \mathrm{g}(2 \\
\text { puff bid) }\end{array}$ & 5 \\
\hline $\begin{array}{l}\text { Salbutamol PRN + fluticasone }(250 \mu \mathrm{g})+ \\
\text { salmeterol }(50 \mu \mathrm{g})(\mathrm{I} \text { puff bid })\end{array}$ & 1 \\
\hline \multicolumn{2}{|l|}{ Moderate persistent asthma } \\
\hline $\begin{array}{l}\text { Salbutamol PRN + beclomethasone } 200 \mu \mathrm{g}(2 \\
\text { puff bid) }\end{array}$ & 4 \\
\hline $\begin{array}{l}\text { Salbutamol PRN + fluticasone }(250 \mu \mathrm{g})+ \\
\text { salmeterol }(50 \mu \mathrm{g})(\mathrm{I} \text { puff bid })\end{array}$ & 4 \\
\hline \multicolumn{2}{|l|}{ Severe persistent asthma } \\
\hline $\begin{array}{l}\text { Salbutamol PRN + beclomethasone } 200 \mu g \text { ( } 2 \\
\text { puff bid) }\end{array}$ & I \\
\hline $\begin{array}{l}\text { Salbutamol PRN + salmeterol }(50 \mu \mathrm{g})(\text { I puff } \\
\text { bid })+ \text { fluticasone }(250 \mu \mathrm{g})\end{array}$ & 2 \\
\hline $\begin{array}{l}\text { Salbutamol PRN + salmeterol (50 } \mu \mathrm{g})(\text { l puff } \\
\text { bid)+ oral steroids + Fluticasone }(250 \mu \mathrm{g})\end{array}$ & 4 \\
\hline $\begin{array}{l}\text { Salbutamol PRN + fluticasone }(250 \mu \mathrm{g})+ \\
\text { salmeterol }(50 \mu \mathrm{g})(\mathrm{I} \text { puff bid })+\text { theophdrine }\end{array}$ & I \\
\hline $\begin{array}{l}\text { Salbutamol PRN + beclomethasone } 200 \mu \mathrm{g}(2 \\
\text { puff bid) + oral steroids }\end{array}$ & 1 \\
\hline
\end{tabular}

Abbreviations: AHMC, Adama Hospital Medical College; PRN, as needed.

patients. Given the increased cost of ICS and low economic status of the people, particularly patients seen at the study unit, it would not be surprising to find association between underutilization of ICS and level of income of the patients. Similar finding have been reported with studies done in the US and Canada even though it is difficult to compare the results due to discordance of socioeconomic characteristics. $^{29}$

Patients with one or more comorbid diseases have experienced increased chance of underutilization of ICS due to different reasons. Use of medications other than ICS could be justification for patients with comorbid diseases which leads them to increased financial burden and underutilization of ICS. Using multiple drugs in addition to anti-asthmatic drugs at the same time can result in complicated and burdensome medication regimens often leading to forgetfulness. Finally physicians might use low doses of ICS due to fear of combined side effects for patients treated for other comorbidities. A similar result is reported elsewhere. ${ }^{30}$
In this study, manner of use of ICS alone or in combination with LABA were significantly related to underutilization of ICS. The guideline recommends increasing the dose of corticosteroids from low to moderate or high when used alone according to the steps of management or severity of the disease. As stated by some physicians, absence of local clinical guidelines in the study setting may be the cause for the physicians not to practice the recommended steps and dose of ICS across stages of asthma treatment. Despite recommendation of combination therapy by the physicians, patients prefer to use ICS alone, mostly due to increased cost of combination therapy, which might be insufficient for the given step of management. ${ }^{31,32}$

Unaffordability of ICS was found to have great impact on ICS use (34.5\%) for underutilization of ICS with respect to patients reported reasons. In this study, both patients and physicians reported increased cost of ICS as a major problem for appropriate use of ICS. This result is in harmony with reports from elsewhere. ${ }^{27,33-35}$ Patients and care providers also reported that inaccessibility of ICS in the study setting was one of the difficulties linked to underutilization of ICS. This might also add to unaffordability of the drug as the patients are forced to buy the drug from private distributors. This finding implies the presence of a loophole which needs attention from the government as well as other concerned bodies.

In the present study, use of ICS only when symptoms arise $(26.2 \%)$ was another reason for underutilization of ICS. Although about $51 \%$ and $33 \%$ of the patients had good knowledge of asthma and ICS respectively, there was no significant association found between knowledge of asthma and ICS and underuse of ICS in this study. Generally patient's good understanding and perception about the disease and its medications could add positive compliance for the patients. This finding matches the idea that lack of understanding about the nature of asthma, and the precise role of ICS in asthma therapy leads to patients using ICS only when symptoms arise as shown in other studies. $^{36,37}$

In this study, patients reported side effects of ICS as a reason for underutilization of ICS (10\%). The same reason was mentioned by some of the physicians. This is in agreement with other studies. ${ }^{25,36}$ However, given that the drug is free of serious side effects, ${ }^{37}$ it looks like that was fear or concern about the side effects rather than experiencing side effects that made most asthma patients use low dose or cease altogether. ${ }^{36}$ This result underscores 
the importance of educating asthma patients focusing on their understanding and attitude toward ICS.

About $10 \%$ of ICS underutilization was attributed to recommendation from physicians. This might be partly due to some physicians underestimating the severity of asthma. ${ }^{25}$ Physicians may also use a lower dose of ICS than recommended in the guideline for special population like elderly due to fear of side effects. ${ }^{30}$ Another issue worth mentioning in this study was about $11.7 \%$ of eligible patients did not take ICS prescription and this finding complies with other studies. ${ }^{19,37,38}$ As was mentioned by some of the physicians, intentional prescription of drugs other than ICS was practiced due to increased cost of ICS and this could be a cause for underprescription. The physicians also stated they prescribed other drugs like oral steroid or theophedrine for "uncontrolled asthma", and in special cases, such as pregnant mothers.

\section{Limitation of the Study}

Since it is a cross-sectional design, it is not possible to find temporal relationship between cause and effect. The study was not multicentered, hence it did not address different population of asthma. Furthermore, due to poor patient flow during the study period it was not possible to attain maximum sample size. In spite of these limitations, the study was able to identify the factors associated with underutilization of ICS from both patients' and physicians' perspectives.

\section{Conclusion}

ICS use has a pivotal role in the management of persistent asthma. Many factors can affect prevalence of ICS use. In the present study, significant underutilization of ICS was observed and monthly income, comorbidity, manner of ICS use, use of ICS only when symptoms arise, unaffordability and inaccessibility of ICS, fear of side effects of ICS, poor knowledge of asthma or ICS, and lack of local guidelines for asthma treatment were the main contributing factors for underutilization of ICS. Therefore, it is very important to prepare local guidelines for asthma management and increase awareness on ICS use and asthma for the patients. Finally concerned bodies should ensure consistent accessibility and affordability of ICS.

\section{Abbreviations}

AHMC, Adama Hospital Medical College; COPD, chronic obstructive pulmonary disease; CRDs, chronic respiratory diseases; ETB, Ethiopian Birr; GINA, Global Initiative for Asthma; ICS, inhaled corticosteroids; LABA, long-acting beta agonist; $\mathrm{MOH}$, Ministry of Health; PHC, primary health care; RVU, Rift Valley University; SPSS, Statistical Package for Social Science.

\section{Role of Sponsors}

Funders did not have any contribution in the study design, collection of data, analysis of data, preparation of manuscript or concerning decision to publish.

\section{Acknowledgments}

We would like to acknowledge Rift Valley University for all the support and funding for the full accomplishment of the research. We also extend our deepest gratitude to all staff members of the Chest Clinic of AHMC.

\section{Author Contributions}

All authors made substantial contributions to conception and design, acquisition of data, or analysis and interpretation of data; took part in drafting the article or revising it critically for important intellectual content; agreed to submit to the current journal; gave final approval of the version to be published; and agree to be accountable for all aspects of the work.

\section{Funding}

This study was supported by Rift Valley University, Adama, Ethiopia.

\section{Disclosure}

The authors declare that they have no conflicts of interest in this work.

\section{References}

1. Global Initiative for Asthma Executive Committee. Global Strategy for asthma management and prevention: 2014 revised. 2006.

2. World Health Organization. The global burden of disease. World Health Organization: 2004 update. 2004.

3. Holgate ST. The epidemic of asthma and allergy. J $R$ Soc Med. 2004;97(3):103-110.

4. Murray CJL, Lopez AD. Global mortality, disability, and the contribution of risk factors: global Burden of Disease Study. Lancet. 1997;349:1436-1442.

5. Musafri S, Joos G, Meerbeeck JV. Asthma, atopic, and COPD in sub-Sahara countries; challenges. East Afr J Public Health. 2011;8:2.

6. Adherence to long-term therapies: evidence for action. World Health Organization; 2003. Available from https://apps.who.int/iris/bitstream/ handle/10665/42682/9241545992.pdf. Accessed August 17, 2020.

7. National Institute of Health, National Heart Lung and Blood Institute. Guidelines for the Diagnosis and Management of Asthma. Washington, DC; 1999.

8. National Asthma Education and Prevention Program. Expert Panel Report 3 (EPR-3): guidelines for the diagnosis and management of asthma - summary report 2007. J Allergy Clin Immunol. 2007;1205 (Suppl):S94-S138. 
9. Smith LA, Bokhour B, Hohman KH, et al. Modifiable risk factors for suboptimal control and controller medication underuse among children with asthma. Pediatrics. 2008;122(4):760-769.

10. Anis AH, Lynd LD, Wang XH, et al. Double trouble: impact of inappropriate use of asthma medication on the use of health care resources. CMAJ. 2001;164(5):625-631.

11. Panettieri RA, Spector SL, Tringale M, Mintz ML. Patients' and primary care physicians' beliefs about asthma control and risk. AllergyAsthma Proc. 2009;30(5):519-528.

12. Lincourt W, Stanford RH, Gilsenan A, DiBenedetti D, Ortega H. Assessing Primary Care Physician's Beliefs and Attitudes of Asthma Exacerbation Treatment and Follow-Up. Open Respir Med J. 2010;4:9-14.

13. Burney P, Potts J, Aït-Khaled N, et al. A multinational study of treatment failures in asthma management. Int $J$ Tuberc Lung Dis. 2008;12:13-18.

14. Mekonnen D, Mossie A. Clinical effects of yoga on asthmatic patients. Ethio j Health Sci. 2010;20:2.

15. Lawson JA, Janssen L, Bruner MW, Hossain A, Joshoa WP. Asthma incidence and risk factor in a national longitudinal sample of adolescent Canadians: prospective cohort studies. BMC Pulm Med. 2014;14:51.

16. Kirubel Z, Kifle W, Gobezie T. Assessing control of asthma in Jimma University Specialized Hospital, Jimma, South West Ethiopia. Ethiop J Health Sci. 2014;24(1):49-58.

17. Ayele Y, Engidawork E, Bayisa T. Assessment of inhaled corticosteroids use and associated factors among asthmatic patients attending Tikur Anbessa Specialized Hospital, Ethiopia. BMC Res Notes. 2017; $10: 314$

18. Boulet LP. Perception of the role and potential side effects of inhaled corticosteroids among asthmatic patients. Chest Journal. 1998;113 (3):587-592.

19. Chambers CV, Markson L, Diamond JJ, Lasch L, Berger M. Health beliefs and compliance with inhaled corticosteroids by asthmatic patients in primary care practices. Respir Med. 1999;93(2):88-94.

20. Barnes PJ. Inhaled glucocorticoids for asthma. $N$ Engl J Med. 2015;332(95):868-875.

21. Laitinen LA, Laitinen A, Haahtela T. A comparative study of the effects of an inhaled corticosteroid, budesonide, and a B-2-agonist, terbutaline, on airway inflammation in newly diagnosed asthma: a randomized, double- blind, parallel-group controlled trial. J Allergy Clin Immunol. 2012;90:32-42.

22. Djukanovic R, Wilson JW, Britten KM, et al. Effect of an inhaled corticosteroid on airway inflammation and symptoms in asthma. Am Rev Respir Dis. 2013;145:669-674.

23. Haahtela T, Jarvinen M, Kava T, et al. Comparison of a B-2-agonist, terbutaline, with an inhaled corticosteroid, budesonide, in newly detected asthma. N Engl J Med. 1991;325:388-392.
24. Selroos O, Pietinalho A, Lofroos A-B, Riska H. Effect of early vs late intervention with inhaled corticosteroids in asthma. Chest. 1995; 108:1228-1234.

25. Liou A, Grubb JR, Schechtman KB, Hamilos DL. Causative and contributive factors to asthma severity and patterns of medication use in patients seeking specialized asthma care. Chest. 2003;124 (5):1781-1788.

26. Laforest L, Pacheco Y, Bousquet J, Kocevar VS, Yin D, Van Ganse E. How appropriate is asthma therapy in general practice? Fundam Clin Pharmacol. 2004;19:107-115.

27. Arumugam V, Preeti K, Vijay J. Drug Utilization Assessment in Asthma Therapy through Prescription Monitoring at Dehradun Hospitals. Indian J Allergy Asthma Immunol. 2008;22(1):15-18.

28. Benkhedera A, Bouachab H, Nafti S, et al. Control of asthma in the Maghreb: results of the AIRMAG study. Respir Med. 2009;103(S2): S12-S20.

29. Apter AJ, Reisine ST, Affleck G, Barrows E, ZuWallack RL. Adherence with twice daily dosing of inhaled steroids: socioeconomic and health-belief differences. Am J Respir Crit Care Med. 1998;157:1810-1817.

30. Jobin MS, Moisan J, Bolduc Y, Dorval E, Boulet LP, Grégoire JP. Factors associated with the appropriate use of asthma drugs. Can Respir J. 2011;18(2):97-104.

31. Sin DD, Tu JV. Underuse of inhaled steroid therapy in elderly patients with asthma. CHEST. 2001;119:720-725.

32. Kelly HW. What is new with the $\beta 2$-agonists: issues in the management of asthma? Ann Pharmacother. 2005;39:931-938.

33. Neffen H, Fritscher C, Cuevas Schacht F, et al. Asthma control in Latin America: the Asthma Insights and Reality in Latin America (AIRLA) survey. Am J Public Health. 2005;17(3):191-197.

34. Vaidya V. Demographic disparities in patient-reported use of inhaled corticosteroids among patients with persistent asthma. J Asthma Allergy. 2010;3:101-106.

35. Rifaat N, Abdel-Hadya E, Hassan A. The golden factors in adherence to inhaled corticosteroids in asthma patients. Egyp J Chest Dis Tuber. 2013;62:371-376.

36. Watson JP, Lewis RA. Is asthma treatment affordable in developing countries? Thorax. 1997;52:605-607.

37. Boulet LP. Perception of the role and potential side effects of inhaled corticosteroids among asthmatic patients. CHEST. 1998;113:58 7-592.

38. Pando S, Lemiere C, Beauchesne MF, Perreault S, Forget A, Blais L. Suboptimal use of inhaled corticosteroids in children with persistent asthma. Inadequate prescription, poor drug adherence, or both? Pharmacotherapy. 2010;30(11):1109-1116.

\section{Publish your work in this journal}

The Journal of Asthma and Allergy is an international, peer-reviewed open-access journal publishing original research, reports, editorials and commentaries on the following topics: Asthma; Pulmonary physiology; Asthma related clinical health; Clinical immunology and the immunological basis of disease; Pharmacological interventions and new therapies. The manuscript management system is completely online and includes a very quick and fair peer-review system, which is all easy to use. Visit http://www.dovepress.com/testimonials.php to read real quotes from published authors. 